\title{
Evaluating Arctic Dialogue: A Case Study of Stakeholder Relations for Sustainable Oil and Gas Development
}

\author{
Muhammad Makki \\ School of Journalism and Communication \& Centre for Social Responsibility in Mining, SMI \\ The University of Queensland, St Lucia QLD 4072, Australia \\ Tel: 61-469-117-543 E-mail: Muhammad.makki@uq.net.au
}

Received: December 27, $2011 \quad$ Accepted: February 1, $2012 \quad$ Published: March 1, 2012

doi:10.5539/jsd.v5n3p34

URL: http://dx.doi.org/10.5539/jsd.v5n3p34

\begin{abstract}
Companies have increasingly adopted stakeholder dialogue and engagement processes to address stakeholder concerns and increase trust, mutual understanding, and to provide better processes of communication regarding their activities. To foster dialogue and increase information sharing between various stakeholders for Arctic oil and gas development, a series of dialogues have been initiated by Bodø Graduate School of Business (Norway), High North Center of Business and Governance (Norway), and public relations firm HBW Resources (USA), called Arctic Dialogue. The purpose of article is to evaluate from the perspective of communication and stakeholder theory. Furthermore the article describes key features and the role of Arctic Dialogue in shaping mutual understanding. In general the findings present an overview of perceptions and impact of the Dialogue process and suggest that Arctic Dialogue is an effective and appropriate activity to integrate stakeholders, information sharing and create mutual understanding.
\end{abstract}

Keywords: Dialogue, Stakeholder, Stakeholder engagement, Arctic, Sustainable development, Oil and gas

\section{Introduction}

Oil and gas (hydrocarbons) are the most important natural resources in the Arctic region and are significantly gaining attention for the future development. Arctic Seabed may hold 25\% of the world's undiscovered oil and gas reserves (Borgerson, 2008). Mostly these hydrocarbon reserves are located in Russian Arctic region: Pechora Basin, Lower Ob Basin, and fields along the Siberian coast (ACIA, 2005). Chukchi Sea, United States, lying between North-western Alaska and Eastern Siberia, is estimated to hold 15 billion barrels of oil and 76 trillion cubic feet of natural gas as technically recoverable resources (Wesley, 2008). In addition, the onshore oil and gas field in Prudhoe Bay area in Alaska are the largest in North America. Moreover, there are significant reserves of natural gas and coal along the North Slope of Alaska. In Canada, oil and gas fields are concentrated mainly in two basins in the Mackenzie Delta/Beaufort Sea region and in the High Arctic, Barents Sea (ACIA, 2005). In Norway, Barent Sea production has commenced in Snøvit gas field and plans have been proposed to develop several promising regions in High North of Norway. Furthermore, Greenland and the Faroe Islands continue to explore for offshore oil and gas development and activities are also starting around Iceland (AMAP, 2007).

In recent times, both extractive companies and Arctic states have found oil and gas development highly promising. There are number of reasons behind: for example, the high prices and increasing demand of oil and gas resources in the global market, extraction becoming more feasible due to advancement in technology and facilities, and Arctic ensuring long term energy security as being a peaceful region (EIA, 2008).

However, there are various contrasting views towards developing these resources because of their anticipated impact upon ecosystem, the environment, local communities, and industries such as fishery. As a result oil and gas companies are facing significant resistance and increasing demand for providing detailed information concerning the social, economic and environmental impacts of their activities. In response there has been increase attention to stakeholder dialogue and the concept is becoming a central aspect of corporate strategy. The approach has particular focus on identification and management of stakeholder relations (Donaldson \& Preston, 1995; Blair, 1998). Furthermore, it has been argued that by adopting a stakeholder approach this can result in competitive advantages in the form of trust and reputation (Rodriguez et al., 2002). Active involvement of the stakeholders in corporate planning and decision making process increases the possibility of successful business operations (Seeger, 1997; Wels \& McGinn, 1998). 
This article (Note) analyses the Arctic Dialogue initiated by Bodø Graduate School of Business, Norway, HBW Resources, USA and High North Center of Business and Governance, Norway, to increase information sharing and mutual understanding between various stakeholders. The findings of the article suggest that the Dialogue have strong foundations based on communication and stakeholder theory. In addition, article presents an informative overview of the impacts and stakeholder perceptions of the Dialogue process. Besides, article raise the interesting potential that Dialogue holds for changing not only social and environmental practices regarding oil and gas development but also relationships between these groups. In general I suggest that Arctic Dialogue is the most effective and appropriate activity to integrate stakeholders and to create mutual understanding to ensure sustainable development in the region. After providing the brief methodology and an overview of stakeholder and communication approaches the article provides an analysis of Arctic Dialogue.

\section{Methodology}

I chose Arctic Dialogue conducted in 22-25th March, 2010 as a case study and carried out applied qualitative research methods (Eisenhardt, 1989; Miles \& Huberman, 1994). The purpose of the study was to assess participant's expectations and perceptions about this activity and to get understanding of the constructed reality to the respondents. Adapted case study approach helped to reflect an understanding of human experience and holistic picture of the situation.

In order to conduct qualitative assessment of the Dialogue 11 semi-structured interviews were conducted during April and May, 2010 with the participants of the Dialogue. While the questions were left as open as possible, to receive more detailed information and views regarding Arctic Dialogue. And this article is also informed by my observation and informal conversations and interaction with participants and organisers of the Dialogue.

The purpose of the study was to understand the views, perceptions and the role of Dialogue towards information sharing and mutual understanding among various stakeholders in regards to sustainable Arctic oil and gas development. All the interviews were organised after the Dialogue in order to gain a deep understanding of stakeholders' views and feedback. In addition, a detailed transcript of Arctic Dialogue with speeches and presentations from both oil and gas industry and other stakeholders were utilised for the research purpose.

\section{The Increasing Emphasis on the Notion of Dialogue}

In order to find out about and address the concerns of stakeholders broader strategies for stakeholder engagement have been developed. Although, many companies focus on dissemination of information to address stakeholder concerns, this process reflects a comparatively weak form of engagement. Scholars argued that dissemination of information rather than participation and interaction suggests companies are themselves defining the information that they see is required for stakeholder understanding rather than reacting to the raised issues and concerns by the stakeholders (Crane \& Livesey, 2003).

Currently, many companies are adopting more interactive form of stakeholder engagement. The concept focuses more on interaction and stakeholder dialogue. Payne and Calton (2002, pp. 121) describe this transition in manager-stakeholder relations as going from 'the need for unilateral managerial cognition and control to a perceived need by some for mutual engagement and new dialogic forms of collective cognition'.

Rockwell (2003, pp. 9) defines dialogue as 'bringing together of diverse voices' and he differentiates three pillars of dialogue. First, dialogue is an 'oral activity' between two or more people. Second, dialogue in a 'written' form represents oral dialogue. Third, a process of 'ineffable dialogue' is the most central notion of the dialogue. This he defines as 'dialogue that is an exchange between individuals or communities through which comes something undefinable but meaningful'. Dialogue is a structured opportunity to discover various approaches about polarizing societal issues. Participants of the dialogue are encouraged to suspend assumptions, cooperate freely, legitimacy of all participants, and openness towards different views (Cissna \& Anderson, 2002; Dessel et al., 2006; Isaacs, 1999). Stakeholder dialogue should be based on an environment that enables participants to interact in the present while recognising the contribution of the past and the unfolding of the future (Dessel et al., 2006). Creating such kind of environment depends on the various adapted factors like choice of the location, establishment of communication and relationship, subject matter of the dialogue, design and facilitation of the dialogue (Adrienne \& Mary, 2008)

In addition, Chapman et al. (2005, pp. 221) differentiates between the concept of 'dialogue' and 'discussion'. Discussion focuses on 'members stating positions, advocating their convictions, convincing others'. The emphasis of discussion is to convince others to specific argument. In contrast, dialogue focuses on openness and willingness towards alternative viewpoints. Isaacs (1994) identifies dialogue 'a climate of openness, free of preconceptions', Drat (1999) argues dialogue is 'the process people engage in when they reveal feelings, explore 
assumptions, suspend convictions and build common ground' (cited in Chapman et al., 2005, pp. 221). Therefore, dialogue is identified as a more advanced form of engagement and businesses are increasingly adopting stakeholder engagement and dialogue strategies that emphasise on mutual responsibility, information-sharing, openness and commitment to problem identification and solutions.

\section{Stakeholder Approach}

The stakeholder approach has extended the perception of organisations and their roles and responsibilities beyond profit maximisation (Foster \& Jonker, 2005). Since the mid-1980s, the stakeholder concept has grown and is acknowledged by not only in academic circles, but also among policy makers, businesses, NGOs and media. Furthermore, it is argued that without continuous engagement and participation of stakeholders based on mutual interdependence companies cannot survive in the long run (Donaldson \& Preston, 1995; Evan \& Freeman, 1988; Clarkson, 1995).

Freeman (1984, pp. 46) defines stakeholders as 'any group or individual who can affect or is affected by the achievements of the organisation's objective'. There are both normative and instrumental reasons for organisations to pay attention to stakeholders. Normative theory proposes that organisations should consider the interests of those who have a stake in the organisation and these interests have intrinsic value (Donaldson \& Preston, 1995). Therefore, the normative literature explains that organisations have moral obligations towards stakeholders (Donaldson \& Dunfee, 1999; Evan \& Freeman, 1988; Freeman \& Phillips, 2002). In contrast, instrumental stakeholder theory explains organisational behaviour as means-end reasoning, where organisations follow their interests through managing stakeholder relationships (Jones, 1995). According to the instrumental positioning of stakeholders, organisations address the interests of those stakeholders who are perceived to have influenced. It is argued that a stakeholder approach based on symmetrical-communication enables the organisation to step into a dialogue and ensure active participation and being a part of a learning process and not just to aim to influence the stakeholders (Morsing \& Schultz, 2006).

Stakeholder identification-To ensure successful business operations it is crucial to identify each and every stakeholder affected and manage these in best possible way. The stakeholder identification process is perceived as a challenge both by practitioners and academics. Scholars usually identify stakeholder into primary and secondary groups (Clarkson, 1995; Hall \& Vredenburg, 2003, Post et al., 2002; Waddock et al., 2002). The primary groups include stakeholders who are crucial for business itself or are bound in formal contract with business: owners, employees, customers and suppliers. The secondary group refers to social and political stakeholders who have a role towards business credibility and acceptance: non-governmental organisations, activists, communities, government and competitors.

Stakeholder management -After the identification of stakeholder, the next challenge is to develop strategies for dealing with stakeholders. The concept of stakeholder management discusses the importance of managing relationship with stakeholder groups on an action oriented base (Freeman, 2005). Several examples of stakeholder management practices have been suggested by Harrison and St. John (1996). Traditional stakeholder management practices help to fulfil stakeholder needs and demands, whereas partnering activities enable firms to create bridges among different stakeholders with contradicting concerns and priorities towards a common objective and problem realisation (Harrison \& St. John, 1996). Although, managing stakeholders and their relationships while addressing their issues and concerns is not an easy task, these objectives can be met in the long run and commitment can be sustained (Freeman, 2007).

Scholars have advised to use term 'stakeholder collaboration' and 'stakeholder enabling' instead of stakeholder management. These constructionist approaches indicate the move from static, instrumental perception towards a more networked organisational perspective. Furthermore, advised terms focus on establishing and maintaining mutually beneficial dialogue where organisations can also be influenced by the process (Calton \& Kurland, 1995; Friedman \& Miles, 2006).

Hence, stakeholder theory provides an appropriate theoretical framework to analyse stakeholder relationship. Since stakeholder approach focuses on participation, inclusion and mutual dependence (Wheeler et al., 2003), so the concepts helps to attain sustainable development.

\section{Communicative Arena - Incorporating Dialogue}

Ingebrigsten and Jakobsen (2007, pp. 266) present a theory called the 'communicative arena'. The main idea behind this theory is to solve the conflicts where economic profitability and competitive solutions collide with social and ecological values. A Communicative arena is an established integrated network where 'it is possible to coordinate interests for the various actors in the economic sectors, while at the same time taking into 
consideration values linked to ecology (nature) and society (culture)'. The theory draws on elements from both Habermas's communicative action theory (1984) and Freeman stakeholder approach (1984). In general, this approach ensures that a dialogue based relation system leads to better solutions than 'one dimensional' and 'competition based' information systems (Ingebrigtsen \& Jakobsen, 2007). The theory of communicative arena argues that stakeholders must be ready to see challenges in other stakeholder's perspective, and realize that the solution should be based on common goods beyond individual interest. Furthermore, participants must be critical to their own views as well as those of others (Poppers, 1981; Ingebrigsten \& Jakobsen, 2007).

Hence, establishing the communicative arena's network with stakeholders will ensure long term solutions. And these networks should use dialogue and cooperation as tools to make decisions (Ingebrigtsen \& Jakobsen, 2007). Some of the requirements of establishing effective communicative arena are;

1) All stakeholders should be allowed to participate.

2) Stakeholders are given the possibility to ask questions about any statement.

3) Stakeholders at any time have the possibility to introduce their own proposals.

4) Stakeholders have the opportunity to express their own attitude, wishes and needs.

5) No stakeholders must be hindered, either by internal or external forces, to make use of the above mentioned rights.

\section{Discovering Arctic Dialogue}

\subsection{Arctic Dialogue - Overview}

In March, 2010 Arctic Dialogue was organised and initiated by Norway's University of Nordland, Bodø Graduate School of Business, High North Center of Business and Governance, Norway and supported by a public relations firm HBW Resources, USA (http://www.hhb.no/ast). The basic theme of the four days activity built on similar previous dialogues aimed at improving communication and understanding among key stakeholders in the Arctic region towards sustainable oil and gas development'.

Arctic Dialogue aimed to cover a broader perspective of oil and gas activities and their ripple effects, and to find solutions to the complex challenges of sustainable development. Around 140 people participated in the Dialogue, including a group of students from Russia and Norway. The objective of the Dialogue was to develop an understanding between oil and gas industry, fisheries and other stakeholders including environmental non-governmental organisations, indigenous people and local, state, national governments to promote learning opportunities. Stakeholders from United States of America, Canada, Norway, Greenland and Russia participated in the Dialogue.

\subsection{Arctic Dialogue - Objectives}

Arctic Dialogue aimed to provide an environment for result oriented conversation where stakeholders from different Arctic countries with different perspective and issues were engaged. In Arctic Dialogue differences and conflicts hold the potential for innovative solutions and the achievement of objectives that eventually benefit all the stakeholders affected by oil and gas activity in the region. The Dialogue aimed to develop mutual understanding and information sharing between stakeholders and intended to achieve particular objectives for sustainable development and sound environmental practices. Also, it provided an environment to share regional experiences from diverse location as the counties of Nordland, Troms and Finnmark in Norway, North Aleutians Alaska, and Sakhlin, Russia to fully examine the benefits and challenges associated with oil and gas activities.

\section{Arctic Dialogue and Changing Relationship between Stakeholders}

The $4^{\text {th }}$ Arctic Dialogue was organised in four discussion group sessions and one working groups. Each session was assigned a facilitator/mediator. The discussion sessions consisted of presentations by the panellists and then discussion was opened for all the participants. The forum was intentionally arranged in a way that maximum interaction could be possible between the participants. Participants had breaks between the presentations and other sessions, and travelling arrangements together in an open environment. This loose environment of whole event was highly appreciated and experienced benefits while communicating with different groups with different backgrounds.

The Arctic Dialogue included various representatives from wide stakeholder groups and focused on issues of economic, environment and society in achieving sustainable development. Participants were managed and aimed for interactive discussion between stakeholders. Following is a list of Dialogue segments, their emphasis and designated participating stakeholders. 
Political and Industry Perspective on the Arctic

- Main focus: Primary issues at stake regarding oil and gas development in the region.

- $\quad$ Panellists/representatives: Norwegian Ministry of Foreign Affairs, Innovation Norway, United States Ambassador to Norway, Statoil Norway, Nordic and Baltic Affairs, United States Department of State, High North Center of Business and Governance, Norway.

- Dialogue Topics: Shifting the frontier of politics, International laws and developments, status and vulnerability of Arctic, long term socio-economic benefits from Arctic oil and gas development, Arctic cooperation and challenges, Primary and secondary economic impacts of oil and gas production, Technical, environmental and other economic issues.

\section{Arctic Governance Session- Principles of Arctic and Eco-System Management}

- $\quad$ Main focus: Issues associated with Arctic governance, Pan Arctic standards, local concerns, indigenous rights and cultures, and the principles of Arctic management

- Panellists/representatives: United States Arctic Research Commission, World Ocean Council, The Organisation of Fisherman and Hunters of Greenland (KNAPK), Norwegian Polar Institute, Arctic Council/PAME (Protection of Arctic Marine Environment).

- Dialogue Topics: Climate change and potential for Arctic resource development, existing governance structure and related issues with policy development, development of Pan Arctic Development Standards for commercial activities, research urgency and coordination with international scientific research, challenges to local, indigenous population and subsistence culture, integration of traditional knowledge of local population in decision making process, building unified principles for Arctic management plan for Arctic countries, sustainable resource management from global perspective.

\section{Energy Fisheries Co-existence Session}

- $\quad$ Main focus: Coexistence, sustainable development of coastal communities and risk mitigation.

- Panellists/representatives: Statoil, Norges Fiskarlag, Norwegian Marine Institute, The Organisation of Fisherman and Hunters, Greenland (KNAPK).

- Dialogue Topics: Technical, environmental and economic impacts on fisheries industry, offshore development and co-existence with fisheries, sustainable coastal communities, past experiences and future challenges, comprehensive involvement of fishing industry in decision making process, building awareness and understanding of both industry's operational activities, impacts of seismic activity on fish population, potential impacts and risk mitigation of oil and gas production on subsistence fishing as a large mammal group.

The findings of the Arctic Dialogue suggests that the activity served as an opportunity for the various stakeholders in Alaska, Greenland, Norway, Canada and Russia, and other stakeholders to share information and experiences. Interacting and hearing the concerns of diverse stakeholder groups was helpful. Participants of the Arctic Dialogue acknowledged that integration of different stakeholders in the oil and gas sustainable development process of Arctic region is crucial. Therefore, Arctic Dialogue provided them with a multistakeholder engagement process and ensured the participation of wide range of stakeholders who have concerns and issues towards any possible oil and gas development. In addition, Dialogue offered an environment where different stakeholders with contrary positions, interests and diverse background were brought to join a common goal in an integrated communication network.

Participants stated that before any possible development in the region there should be detailed ongoing discussions on the issues related issues. To this end, the potential of the Dialogue to provide a forum and to cover the communication gaps within and between the stakeholders was acknowledged. Particularly, indigenous and local communities highly recognised the role of Dialogue as providing them an opportunity to interact and raise their concerns before any development in the region. Though, they did mention that there is significant lack of trust and credibility towards oil and gas industry, but they also acknowledged that these kinds of dialogues will create an environment based on trust and mutual understanding in the long run. To this end, oil and gas industry acknowledged the importance of taking all stakeholders on board as early as possible to create a relationship based on trust and mutual understanding, and this is only possible by these kinds of communication and dialogue platforms.

Respondents raised the importance of Dialogue and its continuation and expansion, which will provide more information about socio-economic benefits and challenges of oil and natural gas developments and associated 
policy issues. Furthermore, the need of research studies and more data was raised to understand where the gaps are and what is needed.

It was mentioned by the respondents that the value of the Dialogue is in bringing people together, so they can express their concerns and come up with answers to many issues. These Dialogues help the stakeholder to learn how to solve some of the problems which occurs in their regions and are very important in a way that stakeholders express their concerns and issues and usually someone has answers or solutions. During the Dialogue many identical issues were discussed by various stakeholders, for example, oil and gas industry and fishery coexistence, experiences of local and indigenous population. This provided spots for mutual understandings and further motivated the participants to learn from each other's experiences and knowledge. In addition, participants from different countries such as the US and Canada, showed an interest in promoting this kind of practice in their regions to ensure sustainability.

Participants from oil and gas industry agreed that the Dialogue has helped them to establish a good relationship on the basis of trust and respect with many of their stakeholders. This activity is the best possible mean to inform stakeholders about different oil and gas issues, rules and regulations, and potential impacts of development. However, these dialogues and their objectives are time consuming and require a lot of resources, but are enormously helpful to create acceptance of development in the region. Specifically, the Dialogue is playing a very important role to bring fishing and petroleum industries to the table to discuss matters of mutual interests. Both these stakeholder groups believe that these activities are helping to develop their relations on the basis of trust and mutual understanding.

Various participants mentioned that the Dialogue as a third party facilitator (initiated by Bodø Graduate School of Business and High North Center of Business and Governance) enabled the emergence of trust, understanding and balancing power influence despite of contrasting views among stakeholders. Also, it helped to develop sense of commitment and ownership: stakeholders act respectfully and transparently and work constructively and cooperatively to move towards a common, mutual understanding and consensus. In general all the participants recognized and appreciated the role of Dialogue and its objectives and believe it to be playing a significant role in future too. However, participants raised the need to focus on achieving some tangible outcomes of the Dialogue.

\section{Discussion}

Dialogue is a form of communication between different people and diverse views and with the intention of learning from each other (Freire, 1970; Rockwell, 2003; Dart, 1999). The participants at the Arctic Dialogue had different and contrasting views towards the oil and gas development and motive of the Dialogue was to share information, experiences and learn from each other. The Dialogue had no objectives to provide solutions or agree on one view or to prevail one view on another but to provide an environment where stakeholders could share information and could identify various challenges regarding proposed development in the region. The activity was organised in a way to provide both time and opportunity to the participants in order to express the issues and concerns regarding the potential impacts of possible oil and gas development in the Arctic region.

The stakeholder management is mostly focusing on satisfying and accepting the concerns and needs of stakeholders, and not giving priority to one stakeholder group over another (Freeman et al., 2007). The Arctic Dialogue was structured in a way to accommodate all the stakeholders by giving them opportunity to express their views and concerns unreservedly. In addition, Dialogue treated all the participants and stakeholders equally without trading any stakeholder group over another. Diverse range of stakeholders and Arctic major players were invited including Arctic head of state, major industry leaders, whaling captains, fishing communities, hunting association, non-governmental organisations, academia, local indigenous and non-indigenous Arctic communities, local politicians and other important stakeholders from different Arctic countries to share information, their experiences and concerns over oil and gas development in the region. The Arctic Dialogue approached and viewed its stakeholders equally regardless what stakes they have in the Dialogue.

The oil and gas industry also showed their commitment towards the communication process with stakeholders. They have been actively involved during the Dialogue, to show their presence and share information. The Dialogue was a unique forum which provided the oil and gas industry to address the concerns of stakeholders, share information and build environment of trust for mutual understanding and sustainability. This stakeholder responsibility can be viewed with respect to stakeholder approach as discussed by Freeman et al. (2007). This approach explains that through communication and close interaction will lead the stakeholders to win-win situation. The industry accepted that this stakeholder approach has helped them to gain acceptance and have led to build relationships between stakeholders with different views and concerns. However, stakeholders have still 
many concerns and there is still trust deficit towards oil and gas industry, but participants including oil and gas industry accepted that these Dialogues are playing important role in developing mutual understanding within and between the stakeholders.

According to Freeman et al. (2007), involving stakeholder in the organisation's action improves the process for decision making. Also, stakeholder involvement will increase possibility of successful action (Welsh \& McGinn, 1998). By increasing the information about the variety of concerns and understandings that the environment might have, these objectives can be met in a long run, and commitment can be sustained (Aldrich \& Herker, 1997). At the Arctic Dialogue diverse range of stakeholder involvement was insured in order to understand various views and challenges towards oil and gas development in the region. Various issues related to ecological, societal and economics were brought in to discussion. To this end, Ingebrigtsen and Jakobsen (2007) also raised the importance of considering the values linked to ecology (nature) and society (culture) with various actors in the economic sector.

The participants at the Arctic Dialogue emphasised on various occasions on the importance of environment protection, culture of local communities and indigenous population, and to ensure the process of sustainable development. The communicative arena also argues that nature and culture should be equally part of the dialogue, especially where economic profitability and competitive solutions are facing difference with society and ecological values (Ingebrigtsen \& Jakobsen, 2007).

Although various stakeholders acknowledged the importance of any oil and gas development in the region in term of development in infrastructure, jobs, revenues, tax etc. and therefore many local communities admitted that these benefits are highly important for the region and supported petroleum activity as well. But also it is important to understand that various stakeholders groups have high concerns regarding damage to environment, spills, loss of opportunities for subsistence living and fading tradition and culture in the area. Therefore stakeholders forecast a large threat in future while working in the coexistence manner with oil and gas industry, hence do oppose any development in the region.

Ingebrigsten and Jakobsen (2007) presented some requirements for communicative arena. The Arctic Dialogue is been analysed on these requirement as: (1) Stakeholder are given the possibility to ask question about any statement: It was appreciated by many participants of the Arctic Dialogue that there were diverse groups of stakeholders invited which ensured varied viewpoints giving. This large mix of stakeholders gave an opportunity to learn from each other's experience and views. In addition, the question and answer sessions during Dialogue was valued by the participants as provided them a chance to understand different views. (2) Stakeholders at any time have the possibility to introduce their own proposal: At the Dialogue every stakeholder was given equal importance and chance to raise their own concerns and issues regarding oil and gas development. Beside their raised concerns, participants also shared possible solutions which could be applicable and acceptable. In addition, many stakeholder groups raised some issues which should be given importance while developing any plan for the development of Arctic region by the government and oil and gas industry. $(3,4)$ Stakeholders have the opportunity to express their own attitudes, wishes and needs; No stakeholders must be hindered, either by internal or external forces, to make use of the above mentioned rights: As mentioned earlier that Arctic Dialogue was designed in a way that equal opportunity was provided to all the participants to openly express their own views and concerns towards oil and gas development in the region. In Dialogue, every stakeholder was treated equally and was not given priority to another group. Furthermore, no stakeholders were hindered to make use of mentioned requirements by Ingebrigtsen and Jakobson (2007) in their communicative arena concept.

Ingebrigsten and Jakobson (2007) together with Habermas (1984) argued that nature and culture should be included in any decision making process. Hence, Arctic Dialogue follows the concept of communicative arena and communicative action and make sure to value these three areas equally in the Dialogue.

However some of the participants and respondents of the Dialogue had concerns on the ecosystem approach followed by the Dialogue, which refers to discussing the technological and environmental issues and ignoring social and cultural dimensions. And, if the principal of communicative arena should be implemented to Arctic Dialogue as the basic theme, these concerns over ecosystem based approach could be overcome and eliminated.

It was realised during the research process that until the three main factors of nature, society and environment and also fulfilling the five requirements presented by Ingebrigsten and Jakobsen (2007), a dialogue cannot be established for the Arctic region. By adopting and implementing the communicative arena concept the stakeholders will consider more recognition and acceptance to the situation, and a result will be more acceptable to other stakeholders. By raising acceptance level, mutual understanding and environment based on trust could be easily achieved. Moreover, Arctic Dialogue is not aiming towards making specific decisions towards future 
oil and gas development in the region but the information sharing and views stated in this Dialogue is mean to how stakeholders analyse the situation and will help them to make a common adaptable decision, 'I might be wrong and you might be right, and by accumulating our efforts, we can move closer to the truth' (Popper, 1981, pp. 251).

\section{Conclusion}

As the findings outlined in this paper demonstrate the Arctic Dialogue has been acknowledged as a positive initiative in terms participants learning and relationship building between oil and gas industry and other stakeholders. Further expansion of Dialogue process may potentially generate new opportunities for learning and engagement between oil and gas industry and other stakeholders. However, it is obvious that to establish a successful dialogue there should be commitment and understanding of what exactly dialogue entails.

The findings confirm that Arctic Dialogue is currently perceived as a significant practice towards the development and holds strong foundation and model of stakeholder approach and communication arena. In view of oil and gas industry, companies have broadened the range of stakeholders with whom they interact. Dialogue, in this regards, has allowed them to develop a broader image of the perceptions and expectations and also increasing level of trust and understanding regarding their activities and actions. Also, finding suggests that Dialogue should be maintained to develop long term mutual understanding and trust.

However, there is a degree of uncertainty regarding the actual outcomes of the Dialogue process. Both theory and practice propose that dialogue enable competing groups to engage with one another and learn different experiences. Still, many participants want to experience tangible outcomes of the Dialogue. In addition, effective dialogue appears to be a relatively slow process and it takes time to establish relationships on mutual understanding and trust from interpersonal level (participants) to inter-organisational level. In this regards, Arctic Dialogue is at relatively early stage in this transition. Furthermore, respondents acknowledged the establishment of Dialogue by third party facilitator and its role towards balancing power influence in shaping dialogue.

\section{Acknowledgments}

Author would like to thank Dr. Anatoli Bourmistrov, Bodø Graduate School of Business, Norway and Andrew Browning, HBW Resources USA, for their role as primary supervisors of the Master Thesis. Thanks are also due as well to author's PhD supervisory team from The University of Queensland; Dr. Kitty van Vuuren, School of Journalism and Communication and Dr. Daniel Franks, Centre for Social Responsibility in Mining, for reviewing and their helpful comments on the early version of this paper.

\section{References}

ACIA. (2005). Arctic Climate Impact Assessment (pp. 1042). Cambridge University Press.

ACIA. (2004). Impacts of a Warming Arctic: Arctic Climate Impact Assessment (pp. 139). Cambridge University Press.

Adrienne, D., \& Mary, E. R. (2008). Evaluation of Intergroup Dialogue: A review of the imperial literature. Conflict resolution quarterly, 26 (2). http://dx.doi.org/10.1002/crq.230

Anderson, A. (2010). Arctic oil and gas drilling ready to take off. NewScientist. [Online] Available: www.newscientist.com/article/mg20727764.300-arctic-oil-and-gas-drilling-ready-to-take-off.html (September 1, 2010)

Calton, J. M., \& Kurland, N. B. (1995). A Theory of Stakeholder Enabling: Giving voice to an emerging postmodern praxis of organizational discourse. In Boje, D. M., Gephart, R. P., \& Thatchenkery, T. J. (Eds), Postmodern Management and Organization Theory (pp. 154-77). London: Sage.

Chapman, C., Ramondt, L., \& Smiley, G. (2005). Strong Community, Deep Learning: Exploring the link. Innovations in Education and Teaching International, 42 (3), 217-230. http://dx.doi.org/10.1080/0158791050016791

Cissna, K. N., \& Anderson, R. (2003). Moments of Meeting: Buber, Rogers, the potential for public dialogue. Albany: State University of New York Press. http://dx.doi.org/10.1002/jhbs.10096

Clarkson, M. B. E. (1995). A Stakeholder Framework for Analysing and Evaluating Corporate Social Performance. Academy of Management Review, 20 (1), 92-117. http://dx.doi.org/10.2307/258888

Crane, A., \& Livesey, S. (2003). Are you talking to me? Stakeholder communication and the risks and rewards of dialogue. In Andriof, J., Waddock, S., Husted, B., \& Sutherland Rahman, S. (Eds.). Unfolding stakeholder 
thinking 2: relationships, communication, reporting and performance (pp. 39-52). Greenleaf Books: Sheffield. [Online] Available: http://www.greenleaf- publishing.com/content/pdfs/ustanwad.pdf

Daft, R. L. (1999). Leadership Theory and Practice.Orlando: Harcourt Brace. [Online] Available: http://onlinelibrary.wiley.com/doi/10.1002/pa.229/pdf

Dessel, A., Rogge, M., \& Garlington, S. (2006). Using Intergroup Dialogue to Promote Social Justice and Change. Social Work, 51 (4), 303-315. http://dx.doi.org/10.1093/sw/51.4.303

Donaldson, T., \& Dunfee, T. W. (1999). Ties that Bind: A social contract approach to business ethics. Boston: Harvard Business School Press, MA. http://dx.doi.org/10.1016/S0378-4266(02)00195-4

Donaldson, T., \& Preston, L. E. (1995). The Stakeholder Theory of the Corporation: Concept, evidence, and implications. Academy of Management Review, 20 (1), 65-91. http://dx.doi.org/10.2307/258887

Driscoll, C., \& Starik, M. (2004). The Primordial Stakeholder: Advancing the conceptual consideration of stakeholder status for the natural environment. Journal of Business Ethics, 49 (1), 65-73. http://dx.doi.org/10.1023/B:BUSI.0000013852.62017.0e

Eisenhardt, K. M. (1989). Building Theories from Case Study Research. Academy of Management Review, 14 (4), 532-550. http://dx.doi.org/10.1108/02651330810904080

Energy Information Administration. (2008). Official Energy Statistics from the U.S. Government. [Online] Available: http://www.eia.doe.gov/emeu/cabs/Canada/Oil.html (viewed 25.08.08)

Evan, W. M., \& Freeman, R. E. (1998). A Stakeholder Theory of the Modern Corporation: Kantian capitalism. In Beauchamp, T., \& Bowie, N. (Eds.), Ethical Theory and Business (pp. 75-93). Prentice Hall, Englewood Cliffs, NJ. http://dx.doi.org/10.1177/000765039703600303

Evan. W. M., \& Freeman, R. E. (1993). A Stakeholder Theory of the Modern Corporation: Kantian Capitalism. In W. M. Hoffman and R. E. Frederick (Eds.), Business Ethics: Readings and cases in corporate morality (3rd ed., pp. 145-54). New York: McGraw-Hill.

Foster, D., \& Jonker, J. (2005). Stakeholder Relationships: The dialogue of engagement. Corporate Governance, 5 (5), 51-57. http://dx.doi.org/10.1108/14720700510630059

Freeman, R. E. (1984). Strategic Management: A Stakeholder Approach. Boston: Pitman, MA.

Freeman, R. E. (2005). Stakeholder Management: Framework and philosophy. In Brønn, P. S. \& Berg, R. W. (Eds). Corporate Communication - A Strategic Approach to Building Reputation (2nd ed.) Gyldendal Akademisk, Oslo. 121-48. http://dx.doi.org/10.1057/palgrave.crr.1540199

Friedman, A. L., \& Miles, S. (2006). Stakeholders: Theory and Practice. New York: Oxford University Press.

Habermas, J. (1984). The Theory of Communicative Action: A critique of functionalist reason (Volume: 2). Translated by Thomas McCarthy. Boston: Beacon Press.

Hall, J., \& Vredenburg, H. (2003). The Challenges of Innovating for Sustainable Development. MIT Sloan Management Review, 45 (1), 61-68.

Harrison, J. S., \& St. John, C. H. (1996). Managing and Partnering with External Stakeholders. Academy of Management Executive, 10 (2), 46-60. [Online] Available: http://www.jstor.org/stable/4165323

Hart, S. L., \& Sharma, S. (2004). Engaging Fringe Stakeholders for Competitive Imagination. Academy of Management Executive, 18 (1), 7-18. http://dx.doi.org/10.1109/EMR.2004.25105

High North Center of Business and Governance. [Online] Available: http://www.hhb.no/index.php?ID=17191

Ingebrigten, S., \& Jakobsen. (2007). Circulation Economics: Theory and Practice. Oxford: Peter Lang Ltd.

Isaacs, W. (1994). The Fifth Discipline Field Book: Strategies and tools for building a learning organization. London: Nicholas Brealey Publishing.

Issacs, W. (1999). Dialogue and the Art of Thinking Together, Currency, New York.

Jon, B., \& Joanne, C. (2006). Assessing the Impact of Stakeholder Dialogue: Changing relationships between NGOs and Companies. Journal of Public Affairs. 6 (3-4), 210-277. http://dx.doi.org/10.1002/pa.229

Jones, T. M. (1995). Instrumental Stakeholder Theory: A synthesis of ethics and economics. Academy of Management Review, 20 (2), 404-437. http://dx.doi.org/10.2307/258852 
Khuri, M. (2004). Facilitating Arab-Jewish Intergroup Dialogue in the College Setting. Race, Ethnicity and Education, 7 (3), 229-250. http://dx.doi.org/10.1080/1361332042000257056

Loy, Wesley. (2008). Record bids for oil, gas leases in Chukchi Sea, Anchorage Daily News (7th Feb 2008). [Online] Available: http://www.adn.com/oil/story/307588.html

Miles, M. B., \& Huberman, A. M. (1994). Qualitative Data Analysis (2nd ed), London: Sage Publications.

Morsing, M., \& Schultz, M. (2006). Stakeholder Communication Strategies. In Morsing, M., \& Beckman, S. C. (Eds), Strategic CSR Communication. (pp. 135-60). Copenhagen: DJØF Publishing.

Morsing, M., Schultz, M., \& Nielsen, K. (2008a). The Catch 22 of Communicating CSR: Findings from a Danish study. Journal of Marketing Communications, $14 \quad$ (2), 97-111 http://dx.doi.org/10.1080/13527260701856608

Oil and Natural Gas Potential in Arctic Region. [Online] Available: http://www.eia.doe.gov/oiaf/analysispaper/arctic/index.html

Payne, S. L., \& Calton, J. M. (2002). Towards a Managerial Practice of Stakeholder Engagement: Developing multi-stakeholder learning dialogues. In Andriof, J., Waddock, S., Husted, B. \& Sutherland Rahman, S. (Eds.). Unfolding stakeholder thinking 2: Relationships, Communication, Reporting and Performance (pp. 39-52) Greenleaf Books: Sheffield. [Online] Available: http://www.greenleafpublishing.com/content/pdfs/ustanwad.pdf

Rockwell, G. (2003). Defining Dialogue: From Socrates to the Internet. NY: Humanity Books, Amherst.

Rodriguez, M. A., Ricart, J. E., \& Sanchez, P. (2002). Sustainable Development and the Sustainability of Competitive Advantage: A dynamic and sustainable view of the firm. Creativity and Innovation Management, 11 (3), 135-146. http://dx.doi.org/10.1111/14678691.00246

Seeger, M. W. (1997). Ethics and Organizational Communication. New Jersey: Hampton Press Inc.

Silvia, A., Miguel, A. R., \& Joan, E. R. (2006). Using stakeholder dialogue as a source for new ideas: A dynamic capability underlying sustainable innovation. Working paper. IESE Business School, WP no. 663, University of Navarra (May, 2006). http://dx.doi.org/10.1108/14720700610689586

Trine, S. J., \& Anne, E. N. (2011). Strategic Stakeholder Dialogue: A discursive perspective on relationship building. Corporate communication: An International Journal. $16 \quad$ (3), 204-217. http://dx.doi.org/10.1108/13563281111156871

University of Nordland and High North Center for Business and Governance bring Energy \& fishing officials together for annual Arctic sea study tour. [Online] Available: http://hbwresources.com/HBW/wp-content/uploads/2010/03/Press-Release-Coexistence

Seminar-May-2008-FINAL.pdf

Waddock, S. A., Bodwell, C., \& Graves, S. B. (2002). Responsibility: The new business imperative. Academy of Management Executive, 6 (2), 132-148. [Online] Available: http://www.jstor.org/stable/4165848

Wheeler, D., Colbert, B., \& Freeman, R. E. (2003). Focusing on Value: Reconciling corporate social responsibility, sustainability, sustainability and stakeholder approach in a network world. Journal of General $\begin{array}{lllll}\text { Management, } & 28 & \text { (3), } & 1-28 . & \text { [Online] }\end{array}$ https://webaccess.wlu.ca/documents/26179/Wheeler_Colbert_\%26_Freeman_2003_Focusing_on_Value.pdf

\section{Note}

The author collected the data presented in this paper during research for a Master of Science in Energy Management at Bodø Graduate School of Business, Norway. At the time of the research author was working as a visiting research scholar and research associate at University of Texas Austin, USA hosted by Consumer Energy Alliance and HBW Resources, USA. 
Table 1. Hydrocarbon activities in the Arctic region

\begin{tabular}{|c|c|}
\hline Country & Area and reserves \\
\hline United States & $\begin{array}{l}\text { Mostly activities are concentrated in Prudhoe bay. } \\
\text { Near shore Fields include: } \\
\text { Endicott oil field - } 582 \text { million barrels (recoverable) } \\
\text { Point Macintyre field - } 400 \text { million barrels (recoverable) } \\
\text { Northstar field - } 176 \text { million barrels (recoverable) } \\
\text { Oooguruk oilfield - } 90 \text { million barrel (recoverable) }\end{array}$ \\
\hline Russia & $\begin{array}{l}\text { Mostly in Western Siberia (Onshore) - } 60 \text { Billion barrels of oil reserves. } \\
\text { Russian Arctic shelves - } 80 \% \text { of Russia potential oil and gas reserves }-1700 \text { trillion } \\
\text { cubic feet approximately natural gas. } \\
\text { Prirazlomnoe oil field- } 83.2 \text { million tonnes of oil (recoverable) } \\
\text { Kolokolmor and Pomor area - } 300 \text { million tonnes of oil (recoverable). }\end{array}$ \\
\hline Canada & $\begin{array}{l}\text { Drake Point onshore }-17.5 \text { Trillion cubic feet of gas. } \\
\text { Terra Nova oil field - } 300 \text { to } 400 \text { million barrels of oil (recoverable) } \\
\text { White rose oil field - } 250 \text { million barrels of oil (recoverable) } \\
\text { Hebarina oil field - } 615 \text { million barrels of oil (recoverable) } \\
\text { Beaufort Sea/Mackenzie Delta - onshore and offshore }\end{array}$ \\
\hline Norway & $\begin{array}{l}\text { Proven oil reserves }-10.2 \text { billion barrels and significant natural gas reserves. } \\
\text { Specifically Barent sea area is the most promising region }\end{array}$ \\
\hline Greenland & $\begin{array}{l}\text { Exploration activities are moving forward. } \\
\text { Nuussuaq Peninsula - significant discovery of hydrocarbons } \\
\text { There remains petroleum perspective area between western Greenland and the east } \\
\text { coast of Canada. }\end{array}$ \\
\hline
\end{tabular}




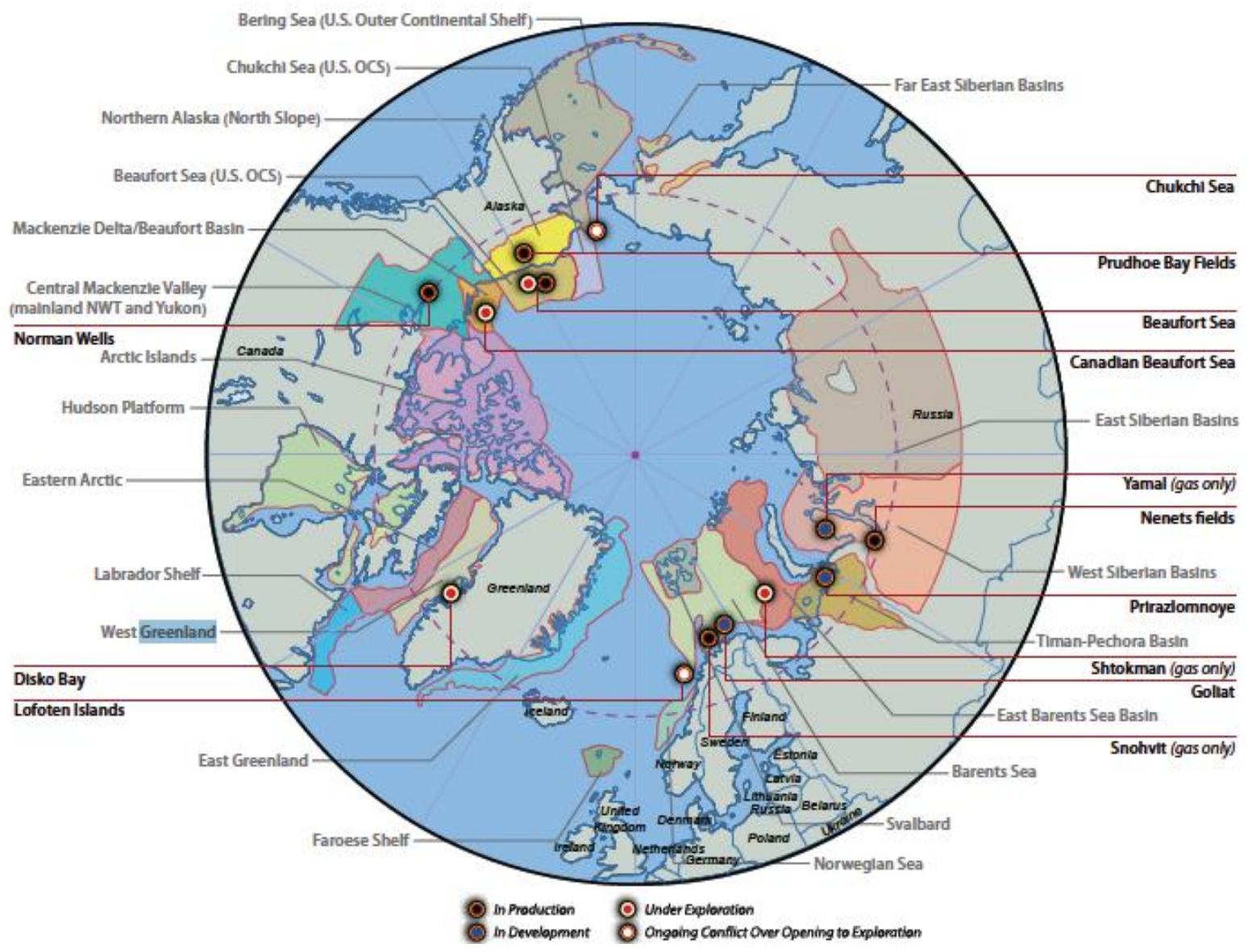

Figure 1. Arctic oil and gas provinces and basins, showing existing and pending production in the Arctic Ocean worldwide (Adapted from AMAP 2008a and Anderson 2010) (p. 34 of Pew Report) 